\title{
Avaliação toxicológica da torta de pinhão-manso Jatropha curcas em ratos*
}

\section{Evaluation of toxicity bran Jatropha curcas}

\author{
Claucia A. Honorato, ${ }^{* *}$ Cesar J.Silva, ${ }^{* * *}$ Simone Mendonça, ${ }^{* * *}$ Mayara Schueroff Siqueira, ${ }^{* *}$ Taline B. S. Catelan ${ }^{* *}$
}

\begin{abstract}
Resumo
O objetivo deste estudo foi avaliar o efeito de dietas acrescidas de torta de pinhão-manso (Jatropha curcas L.) no desempenho e metabolismo de ratos Wistar. Foram utilizados 24 ratos, machos albinos (Rattus norvergicus), em fase de crescimento e com peso médio inicial 109,38 $\pm 6,16 \mathrm{~g}$. Os animais foram pesados e distribuídos aleatoriamente em dois grupos com doze animais, constituindo os tratamentos: controle - dieta comercial e dietas contendo 4,281\%TPM (torta de pinhão manso). O consumo de alimento, ganho em peso e conversão alimentar dos ratos foi depreciado pela inclusão de farelo de pinhão-manso. Observou-se discreto aumento na atividade das enzimas ALT e AST hepática nos ratos alimentados com dietas acrescidas de TPM. Os valores de hemoglobinas e hematócritos encontravam-se dentro deste intervalo considerados adequados para roedores. Não foram reportados diferenças no equilíbrio eletrolítico e no metabolismo respiratório. Conclui-se que a inclusão de torta de pinhão-manso na alimentação de ratos afeta negativamente o desenvolvimento do crescimento e promove alterações deletérias hepáticas.
\end{abstract}

Palavras-chave: toxicidade, hepatotoxidade, alimentação animal.

\begin{abstract}
This study aimed to evaluate the effect of diets plus pie of Jatropha (Jatropha curcas I.) in performance and metabolism of male Wistar rats. 24 rats were used, albino males (Rattus norvegicus) in growth phase and initial average weight $109.38 \pm 6,16 \mathrm{~g}$. The animals were weighed and randomly divided into two groups with 12 animals, constituting the treatments: control - standard diet and diets containing 4, 281TPM. Food consumption, body weight gain and feed conversion ratio of rats has been deprecated by the inclusion of Jatropha bran. The liver enzymes ALT and AST in rats fed diets increased Jatropha. The values of hemoglobin and hematocrit were within this range considered adequate for rodents. Not been reported differences in the electrolytic balance and respiratory metabolism. It is concluded that the inclusion of Jatropha pie in the feeding of rats depresses growth and development promotes hepatic deleterious changes.
\end{abstract}

Keywords: toxic, hepatotoxicity, animal feed.

\section{Introdução}

A grande preocupação com o meio ambiente proporcionou um crescente interesse em fontes de energia alternativas, com a finalidade de substituir os combustíveis de origem fóssil. Dessa forma, podemos notar vários investimentos no ramo do biodiesel, onde plantas oleaginosas são potenciais matérias-primas fontes de biodiesel (Fernandes, 2010), e dentre essas, o pinhão-manso, por seu alto conteúdo de óleo (35 a 45\%), é uma escolha na utilização para a indústria de biocombustível (Achten et al., 2008) e geradora de torta como co-produto.

Jatropha curcas L.(pinhão-manso) pertence à família Euphorbiaceae e é um arbusto de crescimento rápido. Com relação à distribuição geográfica, o pinhão-manso pode ser encontrado em várias regiões intertropicais, e sua fácil adaptação a diversos ambientes fez dele uma boa opção para investimentos em projetos com a agricultura familiar relacionados com o biodiesel (Marsaro et al., 2007). J. curcas L. possui uma grande importância para o Programa Nacional de Produção e Uso de Biodiesel (PNPB), já que tem alto potencial oleaginoso. Existem muitas vantagens no seu cultivo, entre elas o seu alto rendimento e sua produtividade por cerca de 40 anos (Pereira, 2009).

A utilização de sua torta para a alimentação animal seria vantajosa, para agregar valor à indústria do biodiesel. A torta do pinhão-manso, coproduto resultante da extração de seu óleo, é utilizada comumente como adubo orgânico, sendo rica em nitrogênio (Sato et al., 2009). Há um grande interesse sobre o aproveitamento desses coprodutos originados na produção agrícola e agroindústria na alimentação animal, mais especificamente na inclusão em rações concentradas (Gomes, 2007). No entanto, há registro de casos de intoxicação animal pela ingestão de Jatropha curcas L. (Oliveira e Akisue, 2005).

A limitação da utilização desse coproduto como alimento é atribuída à presença de fatores limitantes de natureza tóxica,

\footnotetext{
*Recebido em 15 de dezembro de 2014 e aceito em 19 de abril de 2016.

${ }^{* *}$ Faculdade de Ciências Biológicas e da Saúde, Centro Universitário da Grande Dourados (Unigran).

***EMBRAPA Agropecuária Oeste, Laboratório de Plantas Oleaginosas, BR 163, km 253,6 - Caixa Postal 449, CEP $79804-970$ - Dourados, MS, cesar. silva@embrapa.br.

****Embrapa Agroenergia, Brasília-DF, simone.mendonca@embrapa.br.

Autor de correspondência: Hospital Veterinário, Faculdade de Ciências Biológicas e da Saúde, Medicina Veterinária, Centro Universitário da Grande Dourados - UNIGRAN, Rua Balbina de Matos, 2121, Dourados - Mato Grosso do Sul - MS, CEP: 79.824-900, E mail: clauciahonorato@yahoo.com.br
} 
alergênica e antinutricional (Abdalla et al., 2008). Dentre estes, destaca-se a curcina, ésteres diterpenos, como o éster de forbol e as proteínas com potencial alergênico semelhante à albumina 2S da mamona (Oliveira e Akisue, 2005; MartinezHerrera et al., 2006; Maciel et al., 2007). A atividade tóxica do pinhão-manso deve-se principalmente à presença de ésteres de forbol (Makkar e Becker, 1999; Menezes e Machado, 2007), que é predominante na maioria dos acessos, na faixa de 0,82 a $3,85 \mathrm{mg} / \mathrm{g}$ de albúmen (Makkar et al., 1997 ; MartinezHerrera et al., 2006). Esta substância caracteriza-se como uma complexa mistura de ésteres do forbol tetracíclico diterpeno, que apresentam atividades carcinogênicas e ação inflamatória (Santos et al., 2008).

Silva et al. (2011), estudando níveis de inclusão de torta de

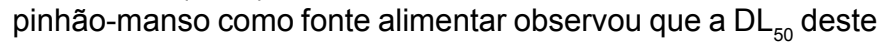
produto está adequada a uma equação cúbica $\left(-0,129 x^{3}+3,45 x^{2}-\right.$ $\left.29,86 x+136,2 ; R^{2}=0,940\right)$ correspondendo a $42,85 \%$ de inclusão. No entanto, não se pode precisar quais são os efeitos deletérios da inclusão deste produto na alimentação animal (Hirota et al., 2010).

Este estudo teve como objetivo avaliar o efeito de dietas acrescidas de torta de pinhão-manso (Jatropha curcas L.) no desempenho e metabolismo de ratos Wistar machos.

\section{Material e métodos}

As tortas de pinhão-manso (TPM), resultantes da extração de óleo por prensa mecânica, foram adquiridas em uma unidade industrial de esmagamento da Fazenda Paraíso, localizada no município de Dourados - MS.

A torta de pinhão-manso foi analisada quanto aos seus teores de umidade, proteína bruta, extrato etéreo e cinzas, conforme metodologia descrita na Association of Official Analytical Chemists (A.O.A.C., 2000). O conteúdo de umidade foi determinado submetendo-se as amostras a $100^{\circ}-105^{\circ} \mathrm{C}$, em estufa até peso constante. $O$ teor de proteína bruta foi obtido pela multiplicação da porcentagem de nitrogênio total, determinado pelo método de Kjeldhall e multiplicado pelo fator 6,25 . Foram determinados níveis de extrato etéreo utilizando-se o aparelho de extração de Soxhlet, tendo-se como solvente o éter de petróleo (p.e. $30-60^{\circ} \mathrm{C}$ ) com refluxo contínuo através da amostra, por 6 horas. A concentração de cinza foi determinada carbonizando-se a amostra em mufla a $600^{\circ} \mathrm{C}$, até peso constante. As análises de éster de forbol foram realizadas no laboratório da Embrapa Agroenergia. Foram utilizados 24 ratos (Processo CEUA261/11), machos albinos (Rattus norvergicus) da linhagem Wistar, provenientes do biotério da Universidade Federal do Mato Grosso do Sul (UFMS), em fase de crescimento e com peso médio inicial $109,38 \pm 6,16 \mathrm{~g}$. Os animais foram mantidos em gaiolas individuais, em sala com temperatura de $26^{\circ} \mathrm{C}$ (ciclo dia:noite 12 horas) e com acesso à ração e água ad libitum, por um período de 21 dias.

A dieta controle para alimentação dos ratos foi uma dieta comercial contendo como ingredientes, milho integral moído, farelo de soja, farelo de trigo, carbonato de cálcio, fosfato bicálcico, cloreto de sódio, premix vitamínico (Vitamina A $12.000,00 \mathrm{UI}$; vitamina D3 1.800,00 UI; vitamina E 30,00 mg; vitamina K3 3,00 mg; vitamina B1 5,00 mg; vitamina B2 6,00 mg; vitamina B6 7,00 mg; vitamina B12 20,00 mcg; niacina 60,00 mg; ácido pantotênico $20,00 \mathrm{mg}$; ácido fólico $1,00 \mathrm{mg}$, biotina 0,05 $\mathrm{mg}$; colina $600,00 \mathrm{mg}$ ) minerais (Ferro $50,00 \mathrm{mg}$; zinco 60,00 $\mathrm{mg}$; cobre $10,00 \mathrm{mg}$; iodo $2,00 \mathrm{mg}$; manganês $60,00 \mathrm{mg}$; selênio 0,05 mg; cobalto 1,50 mg.) e aminoácidos (Lisina 100,00 mg; metionina $300,00 \mathrm{mg}$.). A dieta comercial foi moída e acrescida de $4,281 \%$ TPM $\left(10 \% \mathrm{DL}_{50}\right.$ segundo Nascimento et al., 2010$)$, sequencialmente estas foram umidificadas com água destilada $(30 \%)$ e formadas pelletes que foram secadas em estufa de circulação $\left(65^{\circ} \mathrm{C}\right)$ por 48 horas. Estes foram armazenados em saco plástico e mantidos sob refrigeração para o fornecimento diário de ração para os ratos.

Os ratos utilizados foram pesados e distribuídos aleatoriamente em dois grupos com doze animais, constituindo os tratamentos: controle - dieta comercial e dietas contendo 4,281\%TPM (Tabela 1).

Tabela 1: Composição bromatológica das dietas experimentais

\begin{tabular}{lcc}
\hline & Controle & $\begin{array}{c}\text { \% Torta de } \\
\text { pinhão-manso }\end{array}$ \\
\hline Dieta Comercial & 100 & 95,72 \\
Torta de pinhão-manso & - & 4,28 \\
Umidade (\%) & 12,50 & 12,20 \\
Proteína Bruta (\%) & 22,00 & 22,30 \\
Extrato Etéreo (\%) & 4,50 & 4,88 \\
Matéria Mineral (\%) & 10,00 & 9,87 \\
Matéria Fibrosa (\%) & 8,00 & 9,37 \\
Carboidratos (\%) & 55,50 & 53,58 \\
Energia metabolizável $(\mathrm{kcal} / \mathrm{g})^{2}$ & $3.095,00$ & $3.070,76$ \\
\hline
\end{tabular}

${ }^{1}$ carboidratos=MS-(PB-EE-FB-MM); ${ }^{2} \mathrm{EM}=(\mathrm{PB} \times 3,5)+(\mathrm{EE} \times 8,5)+(\mathrm{ENN} \times 3,5)$

A dieta foi fornecida quatro vezes ao dia para cada rato, podendo assim fornecer a ração de forma que estivesse disponível ao animal. O consumo de ração foi acompanhado durante todo período experimental, para o cálculo de consumo médio diário. A avaliação do crescimento foi realizada através dos parâmetros de peso final, ganho em peso (GP), ganho em peso diário (GPd), consumo alimentar, consumo de proteína, conversão alimentar, taxa de crescimento específico (TCE), taxa de eficiência proteica (TEP) e Sobrevivência (S).

Ao fim do período de alimentação os animais foram anestesiados para a coleta de sangue a fim de realizar as análises bioquímicas. Posteriormente estes foram eutanasiados por anestesia inalatória com halatano (Comitê de ética em experimentação animal - 261/11). A coleta do fígado ocorreu após jejum prévio de 12 horas. $O$ fígado foi pesado e retirada uma amostra para as análises do metabolismo hepático. Com o peso do órgão foi calculado o índice hepatossomático $(\mathrm{IHS})=$ peso do órgão/ peso do animal.

Amostras de fígado foram diluídas em água destilada, na proporção $1 / 10$. Os tecidos foram homogeneizados em homogeneizador mecânico tipo Potter Elvehjem com três "strokes" de 30 segundos a 1.000rpm, sob banho de gelo. 
Após a homogeneização, os extratos foram centrifugados a $13.400 \times g$ por três minutos, determinando as concentrações de proteína totais (Bradford et al., 1976) e teor de aminoácidos livres (Copley (1941). A análise da atividade das enzimas alanina aminotransferase, aspartato aminotransferase foi realizada em amostras de fígado. Estes tecidos foram homogeneizadas com tampão fosfato de sódio $\mathrm{pH} 7,2$. Posteriormente, centrifugados a $4^{\circ} \mathrm{C}$ por três minutos a $600 \times \mathrm{g}$. As atividades das enzimas aspartato aminotransferase e alanina aminotransferase (Reitman e Frankel, 1957).

O delineamento experimental foi o inteiramente casualizado com dois tratamentos e doze repetições. As diferenças entre os grupos foram determinadas pela análise de variância (ANOVA), e quando significativos $(P<0,05)$, comparados pelo teste Tukey.

\section{Resultados e discussão}

O desenvolvimento dos ratos Wistar machos alimentados com a dieta suplementada com 4,3\% TPM encontram-se na Tabela 2.

Tabela 2: Avaliação de desenvolvimento de ratos Wistar (Rattus norvergicus) alimentados com dieta comercial (controle) e com dieta acrescidas de TPM (J. curcas L.)

\begin{tabular}{lcccccccccc}
\hline Índices & \multicolumn{3}{c}{ Controle } & \multicolumn{5}{c}{ Torta PM } \\
\hline Peso inicial & 111,86 & \pm & 5,43 & & 106,90 & \pm & 7,35 & \\
Peso Final & 242,18 & \pm & 16,47 & a & 172,33 & \pm & 12,90 & $b$ \\
Ganho em peso (g) & 130,33 & \pm & 18,48 & a & 65,43 & \pm & 16,21 & $b$ \\
Ganho em peso diário (g) & 5,21 & \pm & 0,74 & a & 2,62 & \pm & 0,65 & $b$ \\
Consumo alimentar (g) & 679,50 & \pm & 0,05 & a & 369,16 & \pm & 0,07 & $b$ \\
Consumo de proteína (g) & 149,49 & \pm & 0,13 & a & 81,66 & \pm & 0,12 & $b$ \\
Conversão alimentar (\% de peso vivo.dia $\left.{ }^{-1}\right)$ & 5,31 & \pm & 0,76 & & 6,00 & \pm & 1,65 & \\
Taxa de crescimento especifico (\%.dia $\left.{ }^{-1}\right)$ & 0,43 & \pm & 0,05 & $a$ & 0,27 & \pm & 0,06 & $b$ \\
Taxa de eficiência protéica & 0,87 & \pm & 0,12 & & 0,80 & \pm & 0,20 & \\
\hline
\end{tabular}

Valores expressos em média \pm de $n=12$ ratos. Letras diferentes distintas na linha reportam diferença significativa pelo teste de Tukey ao nível de $5 \%$ de probabilidade.

O ganho em peso apresentou o mesmo comportamento do consumo de alimen-to, refletindo consequentemente em diferenças na conversão alimentar (Tabela 1).

O desenvolvimento dos ratos Wistar machos alimentados com a dieta suplementada com 4,3\% TPM foi afetado pela inclusão de torta de pinhão-manso. O consumo de alimento dos ratos foi interferido pela inclusão tendo uma diminuição de 45,67\% em relação à dieta controle. O pinhão-manso apresenta substâncias como o látex que é bastante cáustico e possui propriedades antimicrobianas (Sato et al., 2007). Santos et al. (2008) descrevem a ação hipoglicemiante e cicatrizante, a atividade antitumoral, antiinflamatória e larvicida do pinhão-manso, além de suas atividades toxicológicas. Dentre os tóxicos destaca- se a presença do éster de forbol. Este constituintes podem afetar a palatabilidade da dieta interferindo na ingestão. Outro fator pode estar relacionado com as lesões no aparelho digestório dos animais que ingerem por um período dietas acrescidas por torta de pinhão manso, afetando assim a capacidade digestiva.

O consumo e ganho em peso foram deprimidos pela inclusão de torta de pinhão-manso na alimentação. Mariz et al. (2008) observou que a administração de extrato de J. gossypiifolia provocou perda de peso dos ratos seguido de óbito. A perda de peso dos animais é a forma mais comum de demonstração do processo de intoxicação. Santos et al. (2008) relatam que os casos de intoxicação por J. curcas raramente são comprovados, já que a forma de manifestação de intoxicação que são registradas são alterações gástricas, sendo os casos de morte raros devido à diminuição da ingestão. Neste contexto de ingestão de substancias antinutricionais, relatou-se que ratos apresentaram perda de peso, diminuição do crescimento, da conversão alimentar e da taxa de utilização proteica ao consumirem rações que continham inibidores de protease e lectina (Armour et al., 1998).

Observa-se perda de massa do fígado, mas que não refletiu no índice hepatossomático. Esta relação entre peso do animal e peso do fígado não sofreu mudanças devido ao pouco peso adquirido durante a fase experimental (Tabela 3).

Silva et al. (2011) descreve que em ratos submetidos à dose de 30 e $40 \%$ de inclusão de torta de pinhão manso houve aumento de $17,52 \%$ no índice hepatossomático em relação ao grupo controle. Em estudos posteriores com peixes (Fernandes, 2010), frangos (ElBadwi et al., 1995) foram descritos que a alimentação contendo farelo de pinhão-manso provoca alterações hepáticas como sinais de congestão e vários níveis de degeneração e necrose do fígado.
Tabela 3: Parâmetros metabólicos hepáticos de ratos Wistar (Rattus norvergicus) alimentados com dieta comercial (controle) e com dieta acrescidas de TPM (J. curcas L.)

\begin{tabular}{lccccccccc}
\hline Índices & \multicolumn{3}{c}{ Controle } & & \multicolumn{5}{c}{ Torta PM } \\
\hline Peso do fígado & 10,92 & \pm & 1,00 & A & 7,50 & \pm & 1,24 & B \\
Índice hepatossomático & 4,52 & \pm & 0,50 & & 4,34 & \pm & 0,53 & \\
Alanina aminotrasferase (U.L-1) & 315,09 & \pm & 98,3 & & 333,66 & \pm & 132,33 & \\
Aspartato aminotrasferase (U.L-1) & 379,95 & \pm & 94,4 & & 437,23 & \pm & 39,94 & \\
ALT/AST & 0,83 & \pm & 1,04 & & 0,76 & \pm & 3,31 & \\
Proteína hepática (g.dl- $\left.{ }^{-1}\right)$ & 2,03 & \pm & 0,34 & A & 1,41 & \pm & 0,29 & B \\
Aminoácidos hepáticos (umol.g- $\left.{ }^{-1}\right)$ & 2,29 & \pm & 0,91 & B & 3,33 & \pm & 0,52 & A \\
\hline
\end{tabular}

Valores expressos em média \pm de $n=12$ ratos. Letras diferentes distintas na linha reportam diferença significativa pelo teste de Tukey ao nível de $5 \%$ de probabilidade. 
No tecido hepático observou-se diminuição da fração proteica concomitante com o aumento nos teores de aminoácidos livres nos animais submetidos à dieta contendo farelo de pinhão-manso (Tabela 3). No estudo em questão, observou-se um discreto aumento na atividade das enzimas alanina aminotransferase (ALT) e asparto aminotransferase (AST) (Tabela 3). Todos os grupos apresentaram valor de Hemoglobinas e hematócritos dentro do valor de referência (Tabela 4). Não foram reportados diferenças no equilíbrio eletrolítico nos ratos alimentados com dietas acrescidas de TPM(Tabela 4). Nos ratos alimentados com dietas acrescidas TPMobservou-se diminuição dos níveis séricos de potássio (Tabela 4). Não foi observado modificações da dinâmica respiratória e no equilíbrio ácido-básico (Tabela 4).

Tabela 4: Parâmetros sanguíneos, eletrólitos e parâmetros respi-ratórios de ratos Wistar (Rattus norvergicus) alimentados com dieta comercial (controle) e com dieta acrescidas de TPM (J. curcas L.)

\begin{tabular}{|c|c|c|c|c|c|c|}
\hline Parâmetros & \multicolumn{3}{|c|}{ Controle } & \multicolumn{3}{|c|}{ TPM } \\
\hline \multicolumn{7}{|c|}{ Parâmetros hematológicos } \\
\hline Hemoglobina $\left(\mathrm{g} \cdot \mathrm{dL}^{-1}\right)$ & 14,72 & \pm & 0,99 & 14,20 & \pm & 1,88 \\
\hline Hematócrito (\%) & 40,58 & \pm & 0,71 & 41,18 & \pm & 4,42 \\
\hline \multicolumn{7}{|l|}{ Eletrólitos sanguíneos } \\
\hline Sódio (mEq/L) & 133,40 & \pm & 3,66 & 142,78 & \pm & 5,30 \\
\hline Potássio (mEq/L) & 4,04 & \pm & 0,35 & 2,78 & \pm & 0,62 \\
\hline \multicolumn{7}{|l|}{ Parâmetros respiratórios } \\
\hline $\mathrm{pH}$ & 7,38 & \pm & 0,05 & 7,39 & \pm & 0,03 \\
\hline Pressão de $\mathrm{O}_{2}$ & 54,36 & \pm & 12,21 & 43,87 & \pm & 15,09 \\
\hline Pressão de $\mathrm{CO}_{2}$ & 41,16 & \pm & 6,33 & 36,36 & \pm & 4,97 \\
\hline Bicarbonato & 23,80 & \pm & 1,30 & 21,24 & \pm & 2,60 \\
\hline
\end{tabular}

Valores expressos em média \pm de $n=12$ ratos. Letras diferentes distintas na linha reportam diferença significativa pelo teste de Tukey ao nível de $5 \%$ de probabilidade.

As alterações nos parâmetros séricos de aminoácidos livres dos animais submetidos à dieta contendo farelo de pinhãomanso sugerem de degradação proteica para fins energéticos, respaldadas pelo aumento das enzimas ALT e AST. A ALT é uma enzima que catalisa a reação: alanina + alfa-queroglutarato = piruvato + glutamato é encontrada em altas concentrações apenas no citoplasma do fígado, o que torna o seu aumento mais específico de lesão hepática; no entanto, pode estar aumentada em conjunto com a AST em miopatias (doenças musculares) severas. AAST é uma enzima que catalisa a reação: aspartato + alfa-cetoglutarato $=$ oxaloacetato + glutamato. Esta é encontrada em altas concentrações no citoplasma e nas mitocôndrias do fígado, e quando este tecido é danificado, a AST é observada em altas concentrações (Ravel, 1997). Mariz et al. (2006) descreve aumento $21,6 \%$ do valor máximo de referência ( 89 U/L) da AST em ratos tratados dom J. gossypiifolia ressaltando que esta condição decorrer de dano hepático grave, considerando-se que a síntese dessa proteína ocorre exclusivamente nas células hepáticas. Alguns autores relatam que o aumento da AST pode significar distrofia muscular (inclusive no músculo cardíaco) e embolia pulmonar, além de outras condições clínicas (Ravel, 1997; Mariz et al., 2008). Constatou-se que o uso de 4,3\% de inclusão TPM em dietas para ratos provoca diminuição do crescimento e sobrecarga das funções hepáticas dos ratos.

Para Harkness e Wagner (1993), os valores médios de Hemoglobinas para roedores variam de $11 \mathrm{~g} / \mathrm{dL}$ a $18 \mathrm{~g} / \mathrm{dL}$ e os de hematócritos entre $36 \%$ e $48 \%$. Considerando esta referência, todos os grupos apresentaram valor de Hemoglobinas e hematócritos dentro deste intervalo. Não foram reportados diferenças no equilíbrio eletrolítico nos ratos alimentados com dietas acrescidas de farelo de pinhão-manso. Discretas elevações de sódio podem refletir desequilíbrio hidroeletrolítico, possivelmente geradas por diarréias (Mariz et al., 2006). A diminuição dos níveis séricos de potássio neste estudo deve ser atribuída a reduções efetivas no conteúdo corporal de potássio devida a uma menor ingesta de alimento. As manifestações clínicas da hipopotassemia são caracterizadas por fraqueza muscular. Nos ratos alimentados com dietas acrescidas de TPM foi observada piloereção e encontravam-se prostrados.

Não foi observado modificações da dinâmica respiratória e no equilíbrio ácido básico. $\mathrm{A}$ diminuição na $\mathrm{PaO}_{2}$ e $\mathrm{PaCO}_{2}$ como forma de compensação para manter o equilíbrio ácido-básico. Segundo Keen e Gamperl, (2012) as variações $\mathrm{PaO}_{2}$ e $\mathrm{PaCO}_{2}$ podem ser compensadas por alterações cardíacas.

\section{Conclusão}

Conclui-se que a inclusão de torta de pinhão-manso na alimentação de ratos afeta negativamente o crescimento e provoca alterações deletérias hepáticas.

\section{Agradecimentos}

À FINEP, pelo financiamento do projeto 01.10.0015.00.

O estudo foi aprovado pela comissão de bioética e foi realizado de acordo com as normas técnicas de biossegurança e ética. Processo CEUA- 261/11.

\section{Referências}

ABDALLA, A. L.; SILVA FILHO, J. C. D.; GODOI, A. R. D.; CARMO, C. D. A.; EDUARDO, J. L. D. P. Utilização de subprodutos da indústria de biodiesel na alimentação de ruminantes. Revista Brasileira de Zootecnia, v. 37, p. 260 -258, 2008.
ACHTEN, W. M. J.; VERCHOT, L.; FRANKEN, Y. J.; MATHIJS, E.; SINGH, V. P; AERTS, R.; MUYS, B. Jatropha biodiesel production and use. Biomass and Bioenergy, v. 32, p.1063-1084, 2008.

ARMOUR, J. C.; PERERA, R. L.; BUCHAN, W. C.; GRANT, G. Protease Inhibitors and Lectins in Soya Beans and Effects of Aqueous Heat-Treatment. Journal of the Science of Food and Agriculture, v, 78, p. 225-231, 1998. 
ASSOCIATION OF OFFICIAL ANALYTICAL CHEMISTS

(A.O.A.C.). Official Methods of Analysis of AOAC

INTERNATIONAL 18. ed., A.O.A.C. INTERNATIONAL,

Gaithersburg, 2000.

BRADFORD, M. M.; MCRORIE, R. A.; WILLIAM, W. L. A rapid and sensitive method for the quantitation of microgram quantities of protein utilizing the principle of protein-dye binding. Analytical Biochemistry, v, 72, p. 248-254, 1976.

EL-BADWI, S. M. A.; ADAM, S. E. I.; HAPKE, H. J. Comparative toxicity of Ricinus communis and Jatropha curcas in Brown Hisex chicks. Dtsch Tierärztl Wochenschr, v. 102, v. 2, p. 75-77, 1995.

FERNANDES, R. D.O N. Valor nutritivo do farelo de pinhãomanso (Jatropha curcas) para alevinos de tilápia-do-nilo (Oreochromis niloticus). 2010. 81 p .Dissertação (Mestrado em Aquicultura). Centro de Aquicultura da UNESP, Universidade Estadual Paulista, Jaboticabal, 2010.

GOMES, F. H. T. Composição químico-bromatológica e degradação in situ de nutrientes de coprodutos da mamona e do pinhão-manso da cadeia produtiva do biodiesel. 2007. 50 p. Monografia (Graduação em Engenharia Agronômica) Universidade Federal do Ceará, Fortaleza, 2007.

HARKNESS, J.E.; WAGNER, J.E. Biologia e clínica de coelhos e roedores. 3. ed. São Paulo: Roca, 1993, 238 p.

HIROTA, B. C. K.; TREVISAN, R. R.; DIAS, J. F. G.; MIGUEL, M. D.; MIGUEL, O. G.. Fitoquímica e atividades biológicas do gênero Jatropha curcas: minirrevisão. Visão Acadêmica, n. 11, v. 2, p 103-112, 2010.

KEEN, A.N.; GAMPERL, A. K. Blood oxygenation and cardiorespiratory function in steelhead trout (Oncorhynchus mykiss) challenged with an acute temperature increase and zatebradine-induced bradycardia. Journal of Thermal Biology, v. 37, n. 3, p. 201-210, 2012.

MACIEL, F. M.; MACHADO, O. L. T. Avaliação do potencial alergênico de sementes de Jatropha curcas, pinhão-manso. Anais Congresso da rede brasileira de tecnologia de biodiesel, Brasília. DF. (Resumo), 2007.

MAKKAR, H. P. S.; ADERIBIGBE, A. O.; BECKER, K. Comparative evaluation of non-toxic and toxic varieties of Jatropha curcas for chemical composition, digestibility, protein degradability and toxic factors. Food Chemistry, v. 62, p. 207-215, 1998.

MAKKAR, H. P. S.; BECKER, K. Plant toxins and detoxification methods to improve feed quality of tropical seeds - Review. AsianAustralasian. Journal of Animal Sciences, v. 12, p. 467-480, 1999.

MAKKAR, H. P. S.; BECKER, K.; SPORER, F.; WINK, M. Studies on nutritive potential and toxic constituents of different provenances of Jatropha curcas. Journal of Agriculture and Food Chemistry, v. 45, p. 3152-3157, 1997.

MARIZ, S. R.; ARAÚJO, M. S.; CERQUEIRA, G. S.; ARAÚJO, W. C.; DUARTE, J. C.; DINIZ, M. F. F. M.; MEDEIROS, I. A. A. Avaliação histopatológica em ratos após tratamento agudo com o extrato etanólico de partes aéreas de Jatropha gossypiifolia L. Revista Brasileira de Farmacognosia, n.18, v. 2, p. 213-216, 2008.
MARSARO, M. F.; BELETE, N. A. DE S.; SILVA, F. T. C. DA. A potencialidade do pinhão manso na produção de biodiesel no estado do Mato Grosso. Anais Congresso da rede brasileira de tecnologia de biodiesel, Brasília. DF. (Resumo), 2007.

MARTINEZ-HERRERA, J.; SIDDHURAJU, P.; FRANCIS, G.; DAVILA-ORTIZ, G.; BECKER, K. Chemical composition, toxic/ antimetabolic constituents, and effects of different treatments on their levels, in four provenances of Jatropha curcas L. From Mexico. Food Chemistry, n. 96, p. 80-89, 2006.

MENEZES, M. F.; MACHADO, O. L. T. Avaliação do potencial alergênico de sementes de Jatropha Curcas L. Pinhão-Manso. Anais Congresso da rede brasileira de tecnologia de biodiesel, Brasília. DF. (Resumo), 2007.

NASCIMENTO, C.; CORSATO, R. O.; PAEL, F. M.; HONORATO, C. A. Níveis de inclusão de torta de pinhão manso (Jatropha curcas) como fonte alimentar para ratos. Anais II salão de pesquisa docente e $\mathrm{V}$ encontro de iniciação científica. Dourados, MS. (Resumo), 2010.

OLIVEIRA, F.; AKISUE, G. Fundamentos de farmacobotânica. 2. ed. São Paulo: Atheneu, 2005, 152 p.

PEREIRA, C. DE S. S. Avaliação de diferentes tecnologias na extração do óleo do Pinhão-manso (Jatropha curcas L.). Seropédica. 2009. 73 p. Dissertação (Mestrado em Ciência em Engenharia Química). Instituto de Tecnologia, Universidade Federal Rural do Rio de Janeiro, 2009.

RAVEL, R. 1997. Laboratório Clínico: aplicações clínicas dos achados laboratoriais. Guanabara Koogan, 1997, 616 p.

REITMAN, S.; FRANKEL, S. A colorimetric method for determination of serum glutamic oxaloacetic and glutamic pyruvic transaminase. American Journal Clinical Pathology, v. 28, p. 56, 1957.

SANTOS, W. L. C.; DE ASSIS FRANÇA, F.; LOPEZ, L. B.; DA SILVA, G. M. S.; AVELAR, K. E. S.; MORAES, S. R. Atividades farmacológicas e toxicológicas da Jatropha curcas (pinhão manso). Revista Brasileira de Farmacologia, n. 89, v. 4, p. 333336, 2008.

SATO, M.; BUENO, O. D. C.; ESPERANCINI, M.; FRIGO, E. P. A cultura do pinhão-manso (Jatropha curcas L.): uso para fins combustíveis e descrição agronômica. Revista Varia Scientia, v. 7, n. 13, p. 47-62, 2009.

SILVA, D. C.; ALVES, A. A.; DE OLIVEIRA, M. E.; MOREIRA FILHO, M. A.; RODRIGUES, M. M.; SILVA DO VALE, G. E.; SANTOS DO NASCIMENTO, H. T. Consumo e digestibilidade de dietas contendo farelo de mamona destoxificado para ovinos em terminação. Revista Brasileira Saúde Produção Animal, v. 12, n. 1, p. 96-106, 2011. 